\section{How to Treat a Case of Post Coronary Artery Bypass Grafting Presenting with Myocardial Infarction?}

Received: October 17, 2015, Accepted: November 06, 2015, Published: November 14, 2015

\section{How Should I Treat?}

A 78 year old diabetic male who was a case of chronic stable angina had undergone coronary arterial angiogram 4 months back. He was diagnosed as a case of triple vessel disease and had undergone CABG about 3 months back. 1 arterial [Left internal mammary artery (LIMA) to left anterior descending (LAD)] and 3 venous grafts [to diagonal, obtuse marginal (OM) and right coronary artery (RCA)] were used for CABG. He does not have any other comorbid conditions. About 15 days back, he developed severe retrosternal chest pain at rest lasting for 4 hours and since then he is having angina and dyspnea on minimal exertion. His present Electrocardiogram is showing new $Q$ waves with $T$ wave inversion in inferior leads, and echocardiogram is showing new regional wall motion abnormality (RWMA) in inferior wall of left ventricle. We then did a coronary arterial angiogram of native and graft vessels (Figures 1-6) which shows proximal LAD 95-99\% lesion, proximal RCA $100 \%$, proximal OM $150 \%$ lesion, proximal to mid SVG to RCA long segment lesion $95 \%$ ( TIMI 2 flow), variable degree of stenosis of the other graft-native vessel anastomotic points.

1 Should we go for repeat revascularisation or keep the patient only on medical management?

2 If revascularisation is planned, considering the type of lesion, should we plan for redo CABG or $\mathrm{PCI}$ ?

3 If we plan for $\mathrm{PCl}$, should we even attempt native vessel $\mathrm{PCl}$ of RCA in this patient or should we directly plan for $\mathrm{PCl}$ to Saphenous Venous Graft (SVG) to RCA?

4 Should we also attempt $\mathrm{PCl}$ of the other grafts which are showing variable degree of stenosis at the graft - native vessel anastomosis points?

\section{How did I treat? Actual treatment and management of the case}

The patient presented with recent onset chest pain with electrocardiogram showing new $Q$ waves in inferior leads and

\section{Abhisekh Mohanty \\ Interventional Cardiologist, Continental Hospital, Hyderabad, Telengana, India}

\section{Corresponding author:}

Abhisekh Mohanty

”abhisekh.mhnt@gmail.com

Interventional Cardiologist, Continental Hospital, Hyderabad, Telengana, India.

\section{Tel: +919666121115}

Citation: Mohanty A. How to Treat a Case of Post Coronary Artery Bypass Grafting Presenting with Myocardial Infarction?. Interv Cardiol J 2015, 1:1. echocardiogram showing new RWMA in inferior wall of left ventricle. His coronary artery angiogram is showing severe stenosis of SVG to RCA with TIMI 2 flow. There were also variable

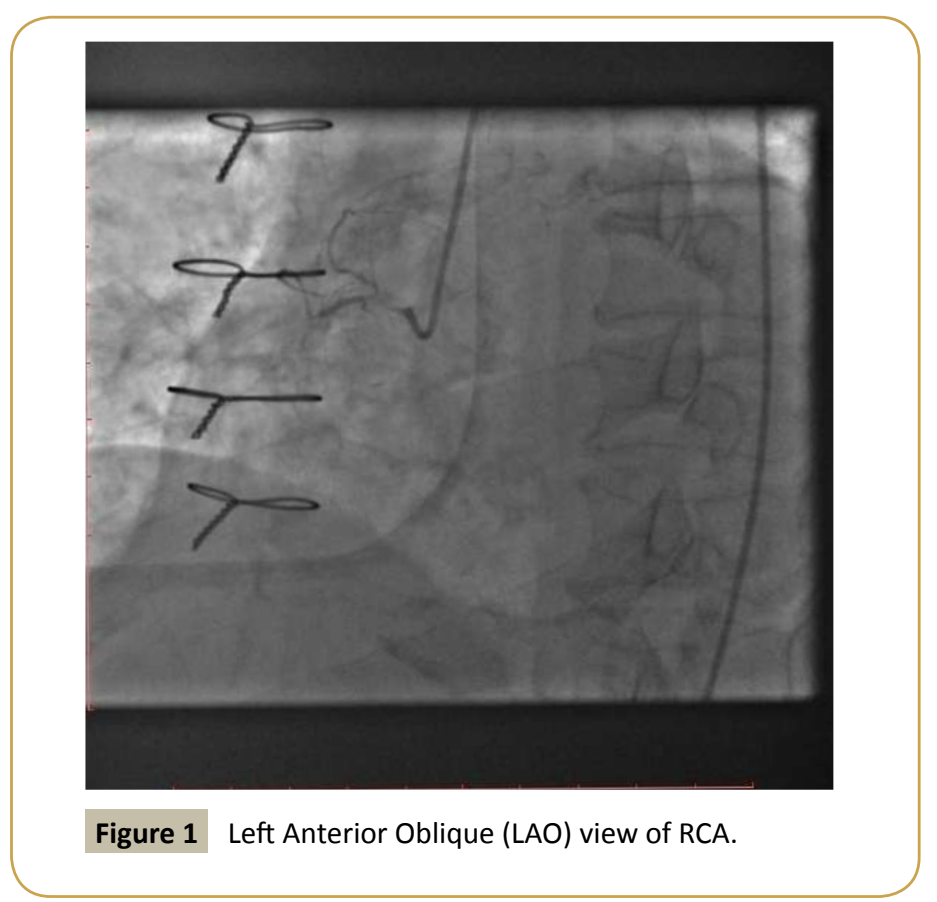




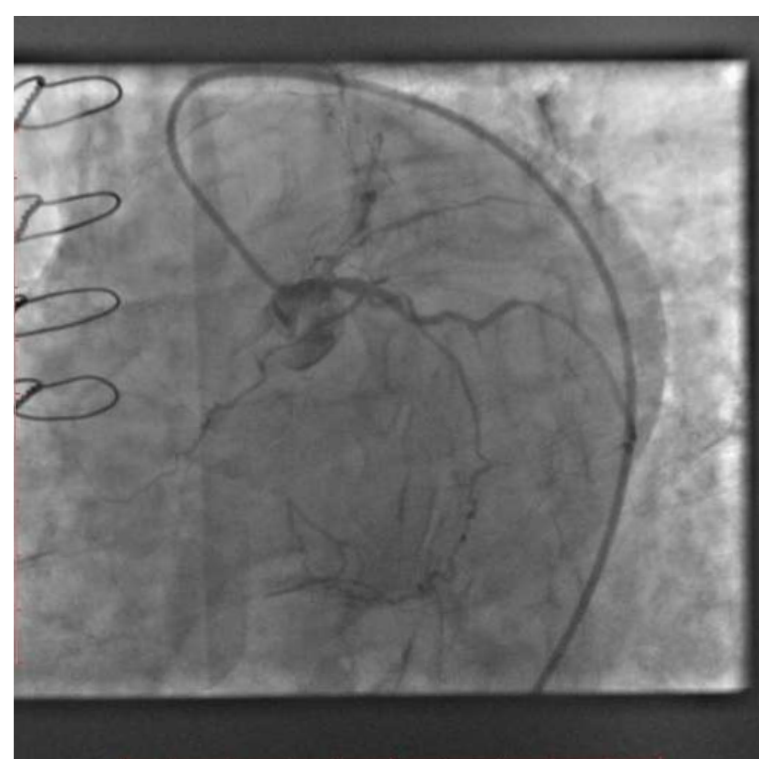

Figure 2 LAO view of left coronary arteries.

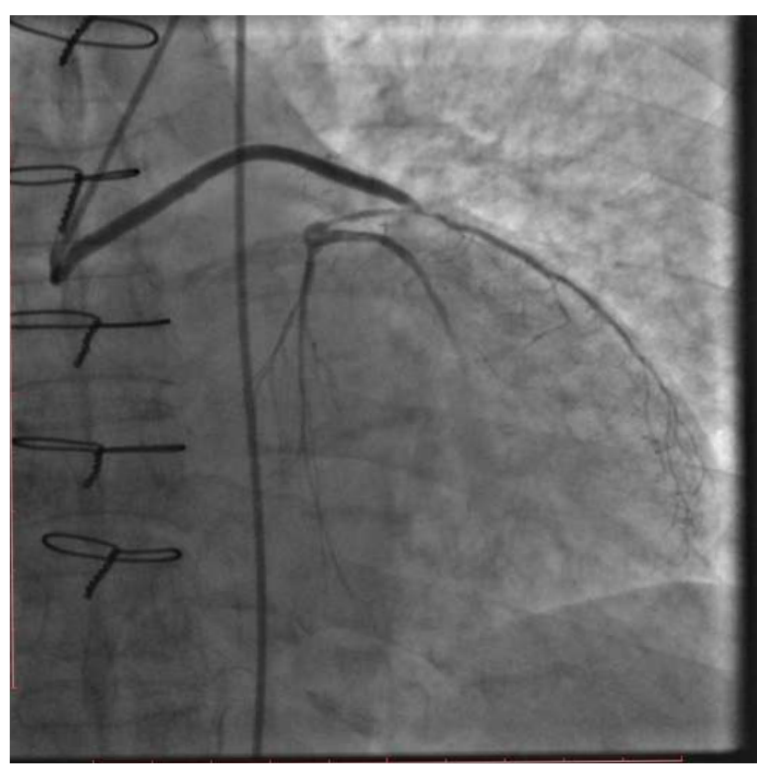

Figure 3 LAO caudal view venous graft to diagonal

degree of stenosis at native vessel and graft vessel anastomosis points, but TIMI 3 flow were maintained in these vessels. Hence in light of the clinical features, electrocardiogram and echocardiogram features, we came to the conclusion that the lesion in SVG to RCA was the culprit lesion.

After discussion with the 'Heart Team' which included the cardiologists and cardiothoracic surgeons it was decided to go for revascularisation rather than medical management only, as it was a case of recent acute coronary syndrome resulting in left ventricular dysfunction.

As shown in previous studies, the mortality and morbidity rate of Redo - CABG is quite high as compared to $\mathrm{PCl}$ [1]. Since this is a

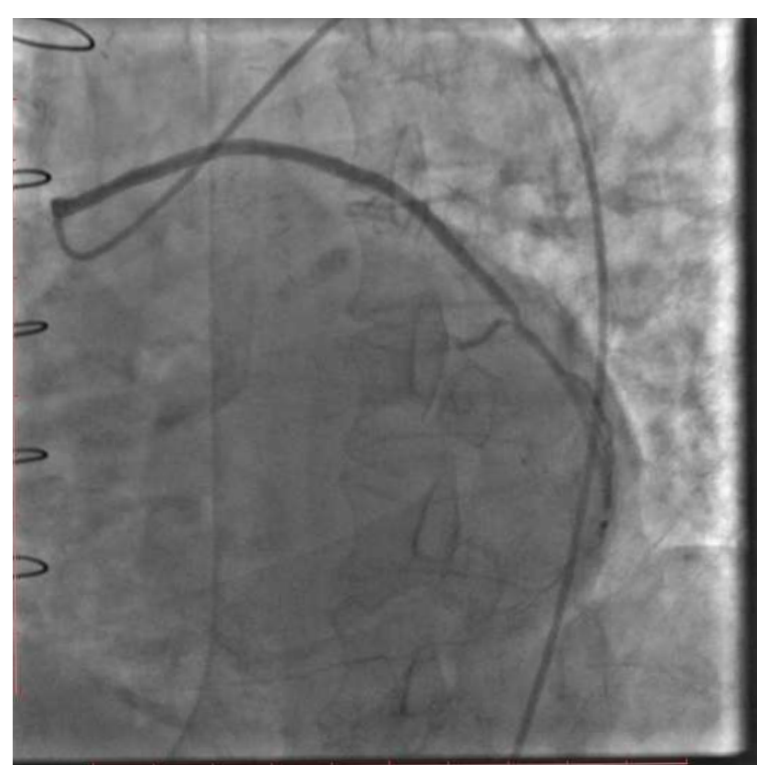

Figure 4 LAO caudal view of venous graft to Obtuse Marginal (OM).

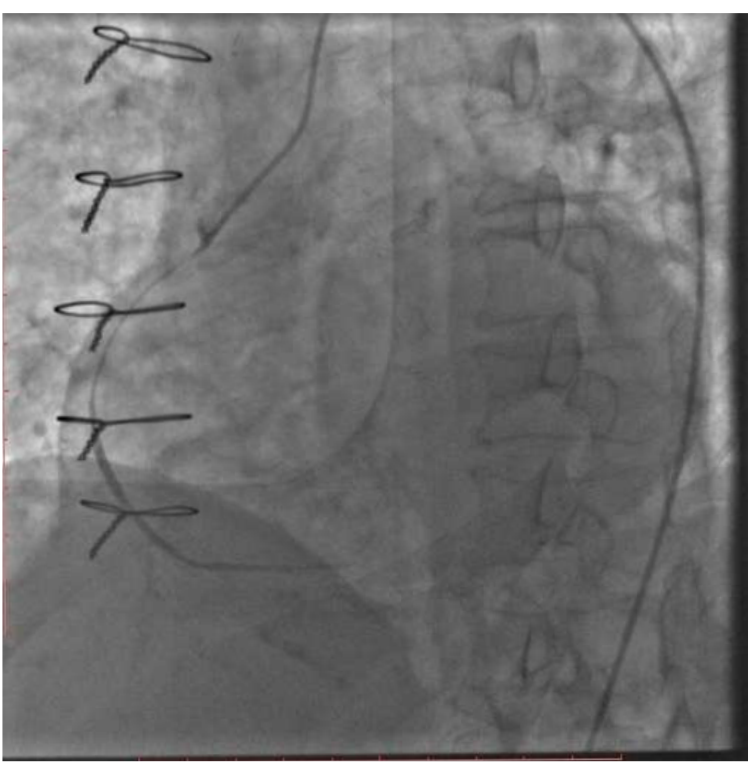

Figure 5 LAO view of SVG to RCA.

78 year old male and the other vessels had TIMI 3 flow, we were of the opinion to do $\mathrm{PCl}$ to revascularize the RCA territory.

There are anonymous results regarding graft vessel $\mathrm{PCI}$. Previous studies have shown that $\mathrm{PCl}$ to native vessel should be preferred over graft vessel $\mathrm{PCl}$ [2]. But in our case the whole of RCA was diseased with a long chronic total occlusion (CTO) segment. Hence we decided not to try native vessel PCl of RCA as the chances of success was less and there was increased risk of contrast induced nephropathy as he was a elderly diabetic patient.

We went ahead with the plan to do PCI to SVG to RCA using distal embolic protection device (filter device) and two overlapping drug eluting stents. We achieved good result with TIMI 3 flow 

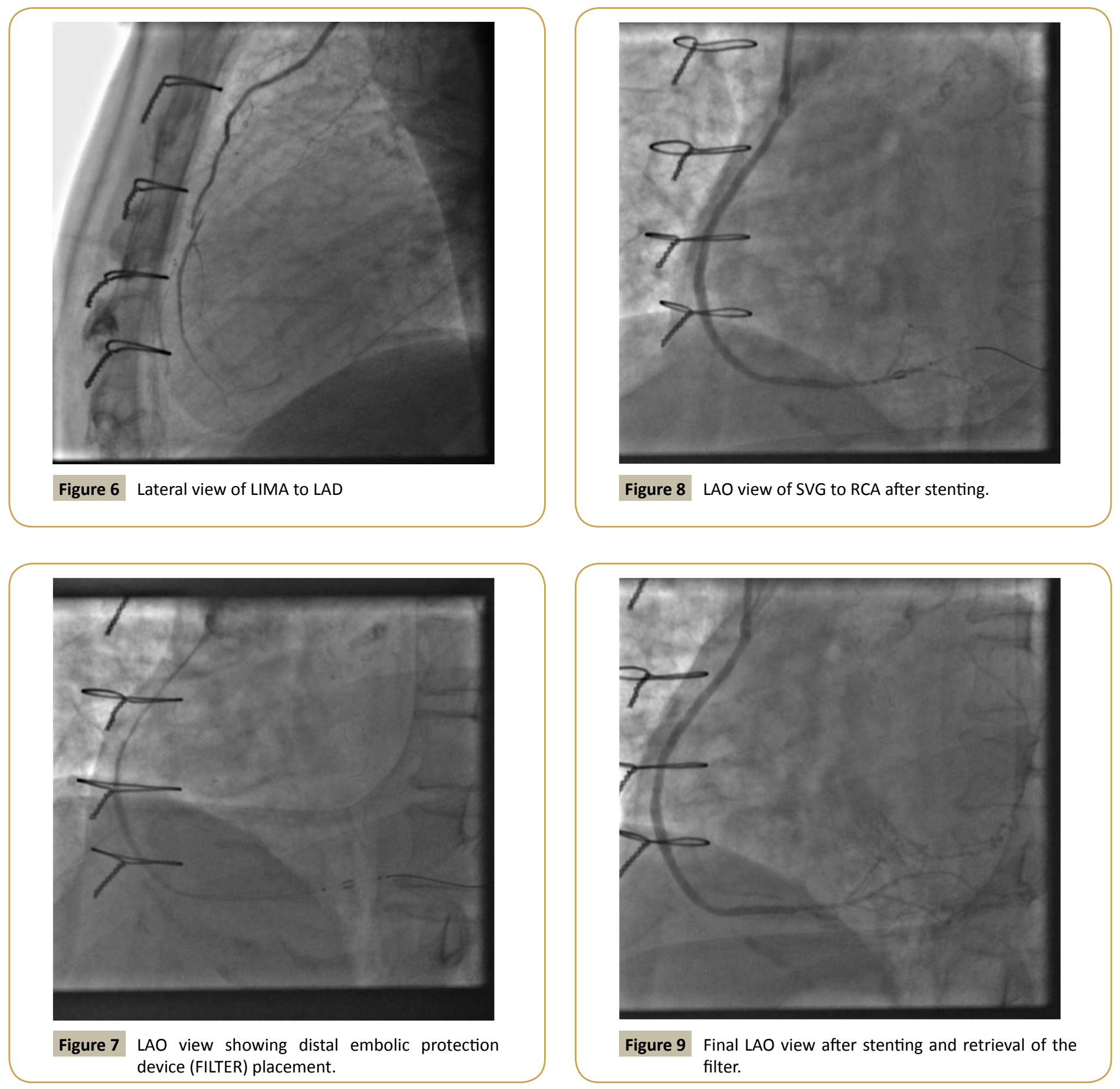

\section{rate (Figures 7-9).}

Since the other graft vessel - anastomotic sites were showing variable degree of stenosis, we did not do anything since TIMI

3 flow was present. We planned to keep the patient on optimal medical management and to get a stress thallium test if the patient becomes symptomatic in future. 


\section{References}

1 Morrison DA, Sethi G, Sacks J (2002) percutaneous coronary intervention versus repeat bypass surgery for patients with medically refractory myocardial ischemia: AWESOME randomized trial and registry experience with postCABG patients. J Am Coll Cardiol 40: 1951-1954.
2 Brilakis ES, Rao SV, Banerjee S (2011) Percutaneous Coronary Intervention in Native Arteries Versus Bypass Grafts in Prior Coronary Artery Bypass Grafting Patients: A Report From the National Cardiovascular Data Registry. J Am Coll Cardiol Intv 4: 844-850. 